\title{
Quercetin synergizes with 2-methoxyestradiol inhibiting cell growth and inducing apoptosis in human prostate cancer cells
}

\author{
GUODONG WANG $^{1 *}$, LIMING SONG $^{1 *}$, HUIPING WANG ${ }^{2}$ and NIANZENG XING ${ }^{1}$ \\ ${ }^{1}$ Department of Urology, Beijing Chaoyang Hospital, Capital Medical University, Beijing 100020; \\ ${ }^{2}$ Department of Reproductive Immunology and Pharmacology, National Research \\ Institute for Family Planning, Beijing 100081, P.R. China
}

Received March 13, 2013; Accepted April 29, 2013

DOI: $10.3892 /$ or.2013.2469

\begin{abstract}
Lack of effective treatment options for castrationresistant prostate cancer reinforces the great need to develop novel drug therapies. Quercetin is a plant-derived flavonoid that can induce apoptosis in prostate cancer cells. 2-Methoxyestradiol (2-ME) is an endogenous estrogenic metabolite that also has antineoplastic activity. However, these two agents have limited bioavailability. Herein, we explored the antiproliferative and proapoptotic activities of quercetin combined with 2-ME in both androgen-dependent LNCaP and androgen-independent PC-3 human prostate cancer cell lines. Compared to quercetin and 2-ME alone, combining quercetin with 2-ME at appropriate concentrations i) showed synergistic antiproliferative and proapoptotic activities; ii) increased $\mathrm{G} 2 / \mathrm{M}$ phase population of cells; iii) decreased the ratio of Bcl-2/Bax significantly. The combination of quercetin and 2-ME is a new clinically relevant treatment regimen which has the potential of enhancing the antitumor effect on prostate cancer and lessening the side effect of either quercetin or 2-ME alone.
\end{abstract}

\section{Introduction}

Prostate cancer is the most common cancer in men, with an estimated 241,740 new cases and 28,170 deaths in 2012 in the United States (1). Cytotoxic chemotherapy based on docetaxel can be used in advanced patients, however, this therapy has only a median overall survival benefit of 2 months $(2,3)$. Lack of effective treatment options for castration-resistant prostate cancer reinforces the great need to develop novel drug therapies that act singly or in combination (4).

Correspondence to: Professor Nianzeng Xing, Department of Urology, Beijing Chaoyang Hospital, Capital Medical University, 8 Gongren Tiyuchang Nanlu, Beijing 100020, P.R. China

E-mail: nianzeng2006@vip.sina.com

*Contributed equally

Key words: quercetin, 2-methoxyestradiol, prostate cancer, combination agents, apoptosis
Quercetin (3, 3', 4', 5, 7-pentahydroxyflavone, Que) is a plant-derived flavonoid which displays antioxidant, antiinflammatory and anticancer properties. It has been reported to induce apoptosis in many human cells, including prostate cancer cells. Although quercetin has already been used to treat advanced prostate cancer as an OTC drug, its clinical use is still limited because of the low bioavailability. Besides modification of its molecular structure to improve bioavailability $(5,6)$, recent studies have been aimed to investigate whether quercetin can enhanced the cytotoxic effect with other chemotherapeutic agents. Several studies demonstrated that the combination of quercetin and classical or new anticancer drugs showed synergistic effect on prostate cancer cells (7-9).

2-Methoxyestradiol (2-ME) is an endogenous metabolite of $17 \beta$-estradiol, which does not exhibit direct estrogenic activity. Many studies have shown that 2-ME has antiproliferative, proapoptotic, and anti-angiogenic activity and is considered to have potential clinical benefit in treatment of cancer. It has been reported that 2-ME inhibited growth and induced apoptosis of both androgen-dependent and androgen-independent prostate cancer cells by blocking cells in G2/M phase (10). 2-ME has also been suggested to inhibit angiogenesis by regulating capillary tube formation in vitro (11). Sweeney et al evaluated the efficacy of 2-ME by administering it orally to hormone refractory prostate cancer patients (12). They found that 2-ME was well tolerated at a dose of $1,200 \mathrm{mg} / \mathrm{d}$, and PSA levels declined or stabilized in a minority of patients. However, the study identified bioavailability as a limiting factor of 2-ME. To overcome this limitation, several studies have investigated whether the efficacy could be enhanced by combining 2-ME with other drugs. Ghosh et al reported that combining 2-ME with eugenol inhibited growth of prostate cancer cells and induced apoptosis at lower concentrations than either single agent alone (13).

Despite these promising data, the effects of combining quercetin with 2-ME on prostate cancer cells are as yet unknown. This study was conducted to investigate the antiproliferative and proapoptotic activities of quercetin combined with 2-ME in both androgen-dependent LNCaP and androgen-independent PC-3 human prostate cancer cell lines. The combined antiproliferative effect was analyzed using the multiple drug equations developed by Chou and Talalay (15). 


\section{Materials and methods}

Cell culture. Two human prostate cell lines, LNCaP and PC-3, were cultured in RPMI-1640 medium (Hyclone, Logan, UT, USA) containing $10 \%$ fetal bovine serum (Hyclone). Cells were incubated in a humidified $\mathrm{CO}_{2}$ incubator at $37^{\circ} \mathrm{C}$ with $95 \%$ air and $5 \% \mathrm{CO}_{2}$.

Drug treatment. Quercetin (Sigma, St. Louis, MO, USA) and 2-methoxyestradiol (Sigma) were dissolved in DMSO (Sigma), and the final concentrations were 3.125-200 $\mu \mathrm{M}$ and $0.3125-10 \mu \mathrm{M}$, respectively. DMSO, in equal amounts to the treatment conditions, was added to the media as the control group.

Cell viability assays and CI calculation. Cells were seeded in 6-well plates at an approximate density of $8 \times 10^{4}$ cells $/ \mathrm{ml}$ for $\mathrm{LNCaP}$ or $3 \times 10^{4}$ cells $/ \mathrm{ml}$ for PC-3 in triplicate. Following attachment (48 and $24 \mathrm{~h}$ after seeding for LNCaP and PC-3, respectively), cells were treated with different concentrations of quercetin $(3.125,6.25,12.5,25,50,100,200 \mu \mathrm{M})$ or $2-\mathrm{ME}$ $(0.3125,0.625,1.25,2.5,5,10 \mu \mathrm{M})$, respectively. Cell viability in the presence and absence of compounds was measured by trypan blue (Sigma) exclusion assay. Briefly, cells were harvested by trypsinization and resuspended in PBS. A small aliquot of cell suspension was added to an equal volume of $0.4 \%$ trypan blue and viable (unstained) cells were counted in a hemacytometer. Cells in each well were counted three times. Cell viability is expressed as the percent viable cells after normalizing to total number of cells in the solvent treated control. Data were analyzed with Origin 7.5 software and dose-effect curve of quercetin or 2-ME on LNCaP or PC-3 cells was drawn, respectively. According to the fitted doseeffect curves and $\mathrm{IC}_{50}$ values, appropriate concentrations of quercetin $(5,10,20,40 \mu \mathrm{M})$ and 2-ME $(0.5,1,3,5 \mu \mathrm{M})$ were selected to compose 16 different combinations using factorial design, which is statistically powered to evaluate effective doses of combination therapy (14). The inhibition rates of cell growth after treatment for $48 \mathrm{~h}$ were measured subsequently. Using a non-constant ratio setting, the combination index (CI) values were calculated on the equation stated below (15):

$$
\mathrm{CI}=(\mathrm{D})_{1} /(\mathrm{Dx})_{1}+(\mathrm{D})_{2} /(\mathrm{Dx})_{2}
$$

$(D)_{1}=$ dose of drug 1 in combination with $(D)_{2} ;(D x)_{1}=$ dose of drug 1 alone; (D) $)_{2}=$ dose of drug 2 in combination with (D) $(\mathrm{Dx})_{2}=$ dose of drug 2 alone. The $\mathrm{CI}$ values are on a continuum with respect to synergy, with values $<0.9$ indicating synergism and values $>1.1$ indicating antagonism for a given combination. According to the CI values, Que $10 \mu \mathrm{M}$, 2-ME $3 \mu \mathrm{M}$, and Que $10 \mu \mathrm{M}$ with 2-ME $3 \mu \mathrm{M}$ which showed synergistic activity were used for the subsequent measurements.

Hoechst 33342 and PI double staining. Cells were plated in $35-\mathrm{mm}$ dishes and treated as described above. After treatment for $48 \mathrm{~h}$, morphological changes on the nuclear chromatin of cells undergoing apoptosis were detected by double-staining with Hoechst 33342 (Sigma) and PI (PI, Sigma). Briefly, the cells were incubated with Hoechst $33342(10 \mu \mathrm{g} / \mathrm{ml})$ in medium for $30 \mathrm{~min}$ at $37^{\circ} \mathrm{C}$, and then incubated with PI $(2 \mu \mathrm{g} /$ $\mathrm{ml}$ ) for $20 \mathrm{~min}$ at $4^{\circ} \mathrm{C}$. Then the cells were examined for morphological changes and were photographed using a Nikon Eclipse TE2000-U fluorescence microscope (Nikon, Tokyo, Japan).

Annexin $V$ binding assay. After treatment for $48 \mathrm{~h}$ as described above, the occurrence of apoptosis was determined by Annexin V-FITC Apoptosis Detection kit (Sigma) according to the manufacturer's instructions. Flow cytometric analysis was performed immediately after supravital staining. Data acquisition and analysis were performed in a BD FACSAria flow cytometer (Becton Dickinson, NJ, USA) using FACSDiva 4.1 software. The presence of viable (Annexin V-negative and PI-negative), early apoptotic (Annexin V-positive, PI-negative), late apoptotic and necrotic (Annexin V-positive and PI-positive) cells were recorded. The extent of apoptosis was quantified as percentage of Annexin V-positive and PI-negative cells.

Cell cycle analysis. Cell cycle distribution was analyzed by flow cytometry using PI DNA staining. After treatment for $48 \mathrm{~h}$, cells were harvested and resuspended in ice-cold PBS. Ice-cold $70 \%$ ethanol $(4 \mathrm{ml})$ was added in a drop wise manner and cells were stored at $4^{\circ} \mathrm{C}$ for $2 \mathrm{~h}$. Then, cells were pelleted by centrifugation for $5 \mathrm{~min}$. The supernatant was removed and cells were resuspended in $1 \mathrm{ml}$ of $0.002 \%$ RNAse solution $(0.002 \%$ RNAse $+0.1 \%$ TritonX-100 + 0.01 M PBS) incubated at $37^{\circ} \mathrm{C}, 5 \% \mathrm{CO}_{2}$ for $30 \mathrm{~min}$. Then $0.1 \mathrm{ml}$ of PI solution $(0.05 \%$ PI $+1 \%$ TritonX-100 + 0.01 M PBS) was added. Subsequently, cells were analyzed by Coulter ${ }^{\circledR}$ Epics XL flow cytometer (Beckman Coulter Inc., CA, USA). Cell cycle distribution was calculated from at least $8 \times 10^{4}$ cells and was analyzed with MultiCycle software by assigning relative DNA content per cell to sub-G0/G1, G0/G1, S and G2/M fractions.

Western blot experiments. After treated with indicated concentrations of drugs for $48 \mathrm{~h}$, total cell proteins were extracted from cells with RIPA Lysis buffer (Applygen Inc., Beijing, China) added with protease inhibitor (Roche, Switzerland) according to the manufacturer's instructions. Cellular protein concentration was determined using the BCA protein assay kit (Pierce, Rockford, USA) according the manufacturer's instructions. Equivalent amounts of protein samples $(80 \mu \mathrm{g})$ were separated with $15 \%$ SDS-PAGE gels and transferred to nitrocellulose membranes (Pall, NY, USA). Following primary antibodies: Bcl-2 (Santa Cruz, CA, USA), Bax (Santa Cruz) and $\beta$-actin (Santa Cruz) were used. After binding to indicated secondary antibodies, an enhanced chemiluminescence (Pierce) blotting analysis system (Geldoc, Bio-Rad, CA, USA) was used for antigen-antibody detection.

Statistical analysis. Data were expressed as means \pm SD. Between-group comparisons were analyzed by ANOVA using SPSS Statistics 17.0. P-values $<0.05$ were regarded as a significant difference.

\section{Results}

Inhibition of cell growth. The effects of quercetin or 2-ME alone on cell viability in $\mathrm{LNCaP}$ or $\mathrm{PC}-3$ prostate cancer cells were measured, respectively. As shown in Fig. 1, the inhibi- 

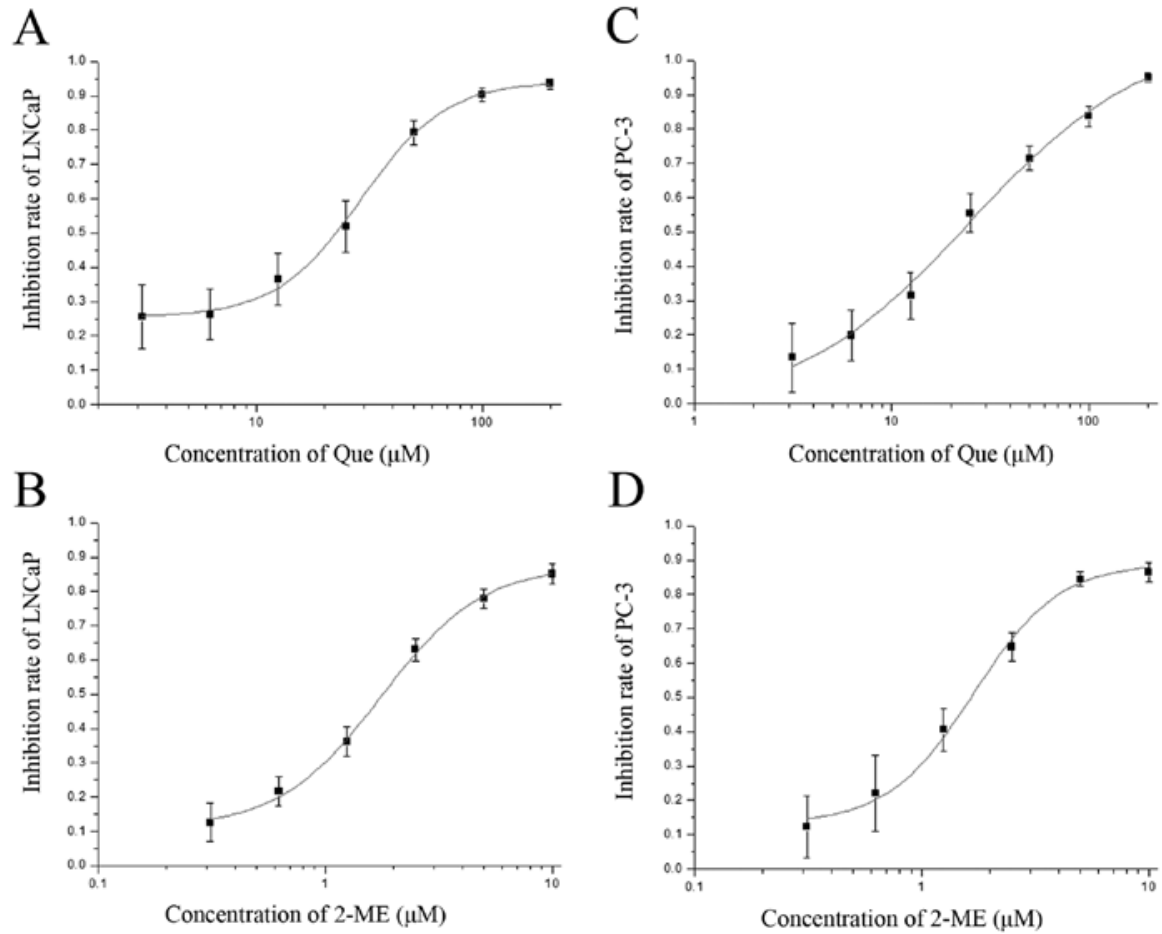

Figure 1. Dose-effect curves of quercetin or 2-ME on $\mathrm{LNCaP}(\mathrm{A}$ and $\mathrm{B})$ or PC-3 (C and D) cells. Cells were cultured as described in Materials and methods and treated with varying combinations of quercetin $(3.125,6.25,12.5,25,50,100,200 \mu \mathrm{M})$ or $2-\mathrm{ME}(0.3125,0.625,1.25,2.5,5,10 \mu \mathrm{M})$. After treatment for $48 \mathrm{~h}$, inhibition rate of cell growth was measured. Dose-effect curves were fitted and $\mathrm{IC}_{50}$ values were calculated using origin 7.5 software.
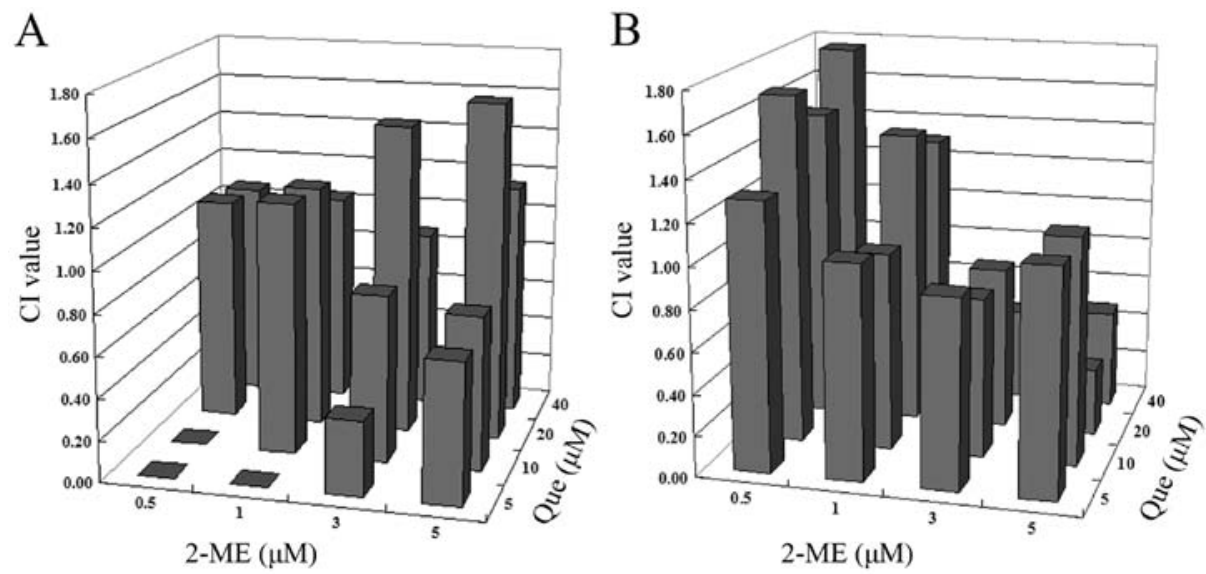

Figure 2. CI values for the combinations of quercetin and 2-ME on LNCaP (A) or PC-3 (B) cells. Cells were cultured as described in Materials and methods and treated with varying combinations of quercetin $(5,10,20,40 \mu \mathrm{M})$ and 2-ME $(0.5,1,3,5 \mu \mathrm{M})$. After treatment for $48 \mathrm{~h}$, cell viability was measured and the CI values were determined using the equation described in Materials and methods. In (A), CI values for combinations of Que $5 \mu \mathrm{M}+2-\mathrm{ME} 0.5 \mu \mathrm{M}$, Que $5 \mu \mathrm{M}+2$-ME $1 \mu \mathrm{M}$, and Que $10 \mu \mathrm{M}+2$-ME $0.5 \mu \mathrm{M}$ were not available using the present method.

tion rate of $\mathrm{LNCaP}$ or $\mathrm{PC}-3$ cells treated with varying doses of quercetin or 2-ME showed a dose-dependent increase. For $\mathrm{LNCaP}$ cells, the $\mathrm{IC}_{50}$ values of quercetin and 2-ME were $23.29 \mu \mathrm{M}$ and $1.89 \mu \mathrm{M}$, respectively. For PC-3 cells, the $\mathrm{IC}_{50}$ values of quercetin and 2-ME were $22.12 \mu \mathrm{M}$ and $1.74 \mu \mathrm{M}$, respectively. Then the effects of 16 combinations of quercetin $(5,10,20,40 \mu \mathrm{M})$ and $2-\mathrm{ME}(0.5,1,3,5 \mu \mathrm{M})$ on cell growth were measured. CI values were calculated and shown in Fig. 2. The combination treatments demonstrated CI values of 0.36-2.18 and 0.32-1.77 for LNCaP and PC-3 cells, respectively. According to the CI values, lower dose of quercetin
(5 and $10 \mu \mathrm{M}$ ) with higher dose of 2-ME ( 3 and $5 \mu \mathrm{M}$ ) for LNCaP cells showed synergistic activity, whereas for PC-3 cells, besides the combination of Que $10 \mu \mathrm{M}$ and 2-ME $3 \mu \mathrm{M}$, higer dose of quercetin $(20$ and $40 \mu \mathrm{M})$ with higher dose of 2-ME ( 3 and $5 \mu \mathrm{M}$ ) showed synergistic activity. The combination of Que $10 \mu \mathrm{M}$ and 2-ME $3 \mu \mathrm{M}$ which showed synergism ( $\mathrm{CI}=0.81$ for $\mathrm{LNCaP}$; $\mathrm{CI}=0.78$ for $\mathrm{PC}-3$ ) was used for the subsequent measurements.

Morphological detection of apoptosis by Hoechst 33342 and PI staining. Normal cells stained with Hoechst showed normal 
A

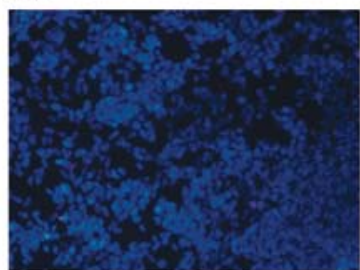

E

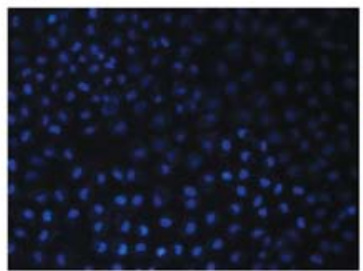

B

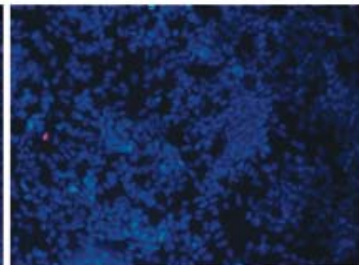

$\mathrm{F}$

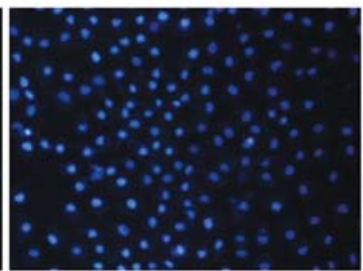

$\mathrm{C}$

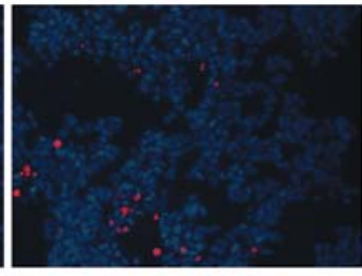

G

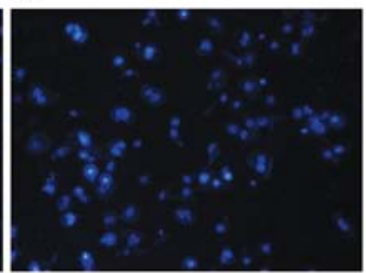

$\mathrm{D}$

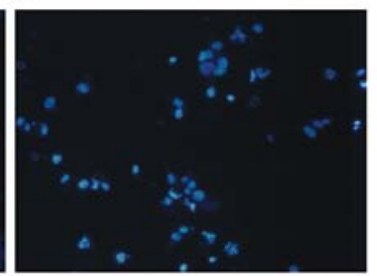

$\mathrm{H}$

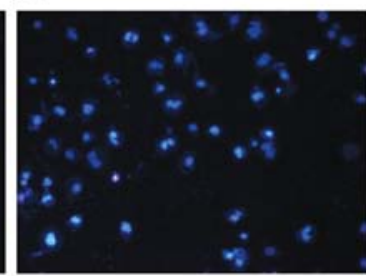

Figure 3. Hoechst 33342/PI double staining in LNCaP (A-D) or PC-3 (E-H) cells. (A and E) Control cells; (B and F) cells were treated with Que $10 \mu \mathrm{M}$ for $48 \mathrm{~h}$; $(\mathrm{C}$ and $\mathrm{G})$ cells were treated with 2-ME $3 \mu \mathrm{M}$ for $48 \mathrm{~h}$; (D and H) cells were treated with Que $10 \mu \mathrm{M}+2-\mathrm{ME} 3 \mu \mathrm{M}$ for $48 \mathrm{~h}$. Cells were photographed using a fluorescence microscope (x200). Representative data of three independent experiments are shown.
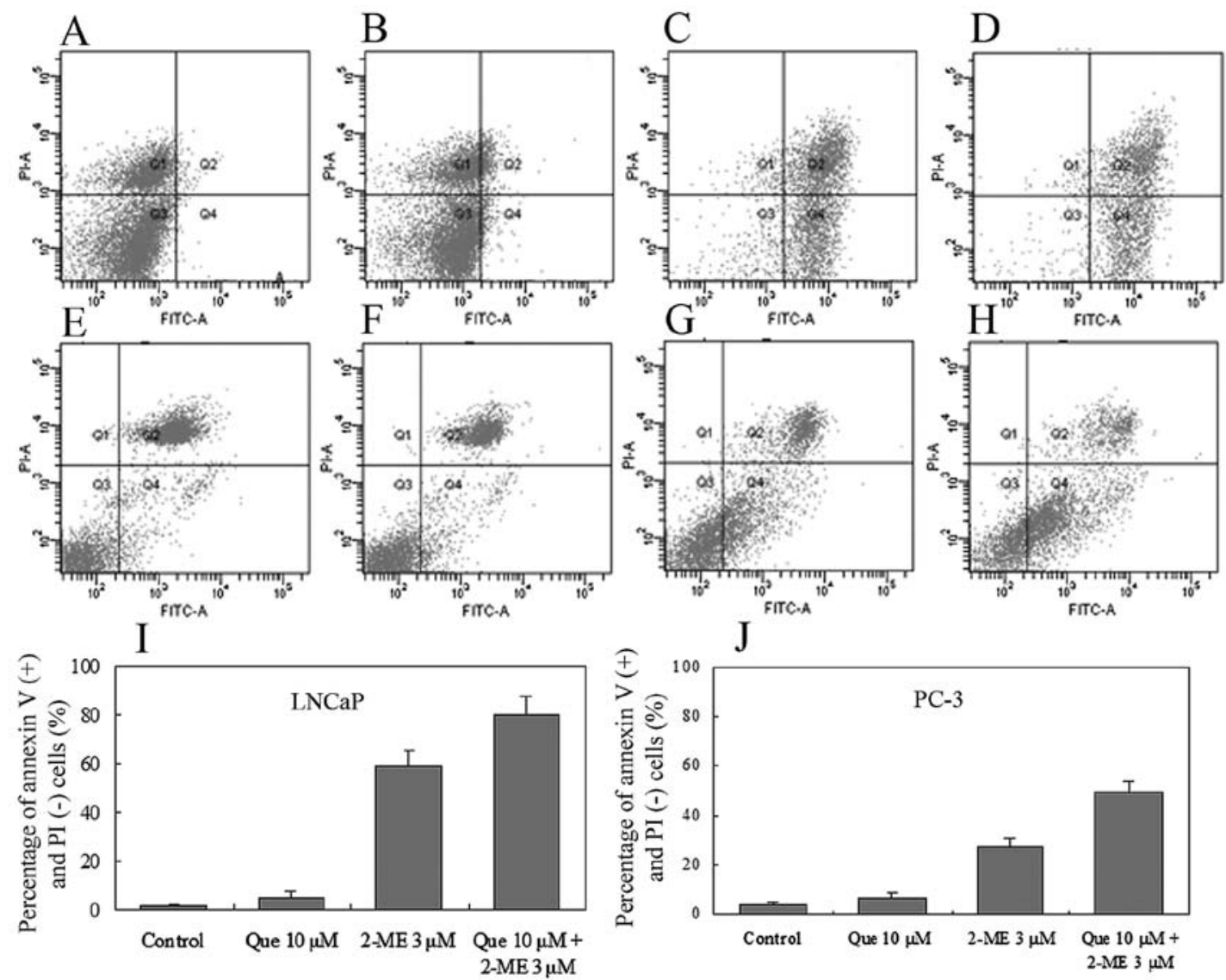

Figure 4. Apoptosis induced by quercetin, 2-ME or combination in LNCaP (A-D) or PC-3 (E-H) cells. (A and E) control cells; (B and F) cells were treated with Que $10 \mu \mathrm{M}$ for $48 \mathrm{~h}$; (C and G) cells were treated with 2-ME $3 \mu \mathrm{M}$ for $48 \mathrm{~h}$; (D and $\mathrm{H})$ cells were treated with Que $10 \mu \mathrm{M}+2-\mathrm{ME} 3 \mu \mathrm{M}$ for $48 \mathrm{~h}$. Data are presented as means \pm SD from triplicate of percentage of Annexin V-FITC positive and PI negative and cells (I and J).

morphology of nuclei (blue), while apoptotic cells showed nuclear condensation or nuclear fragmentation (bright blue). PI can penetrate the cytoplasmic membrane of late apoptotic and necrotic cells (pink). As shown in Fig. 3, in both LNCaP and PC-3 cells, slight nuclear condensation or nuclear fragmentation were observed in control cells and cells treated with Que $(10 \mu \mathrm{M})$ alone. In contrast, a large number of cells showed these morphological changes after treatment with $2-\mathrm{ME} 3 \mu \mathrm{M}$ or with the combination of Que $10 \mu \mathrm{M}$ and 2-ME $3 \mu \mathrm{M}$.

Apoptotic effect is induced by quercetin with 2-ME treatment. We examined whether the combination treatment for $48 \mathrm{~h}$ could enhance the apoptotic effect in LNCaP and PC-3 
A

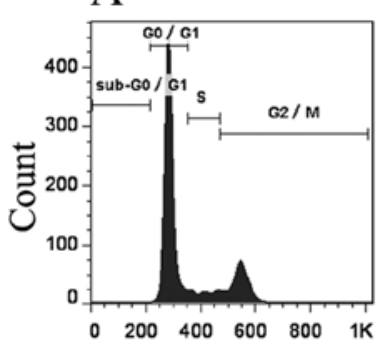

$\mathrm{E}$

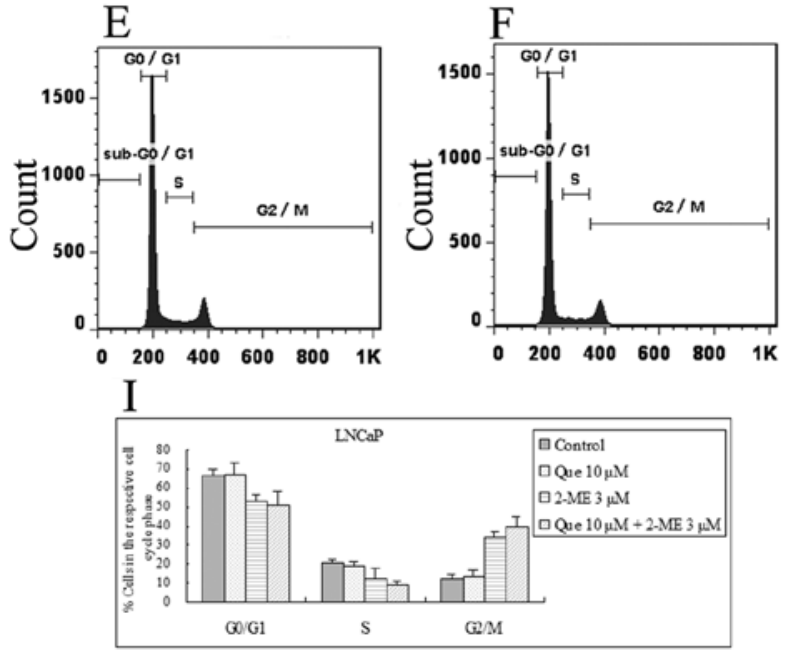

C

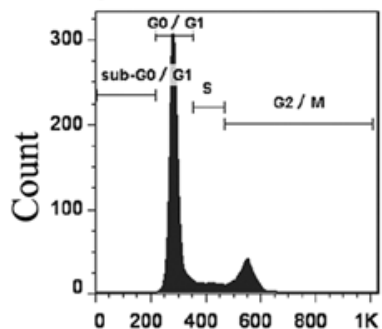

$\mathrm{F}$

G

D
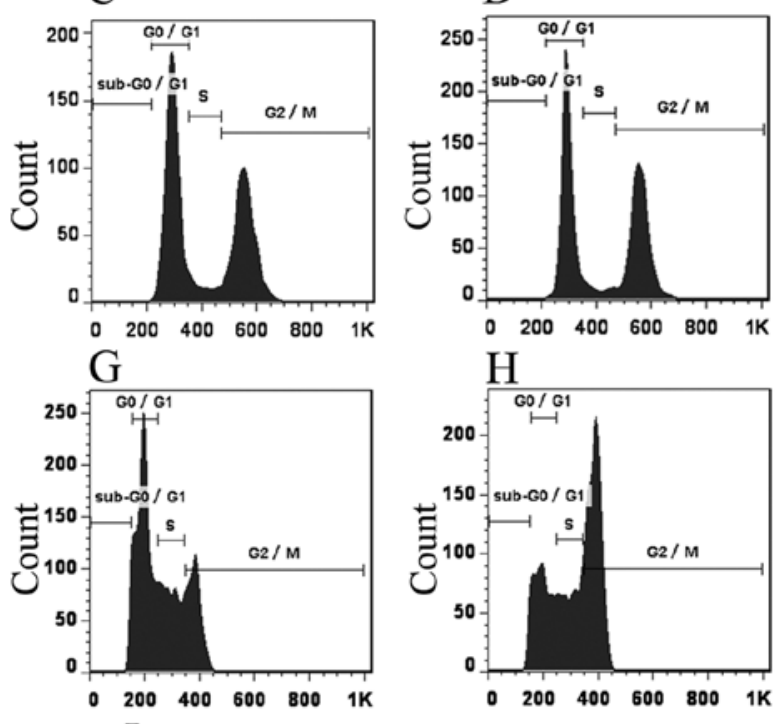

J

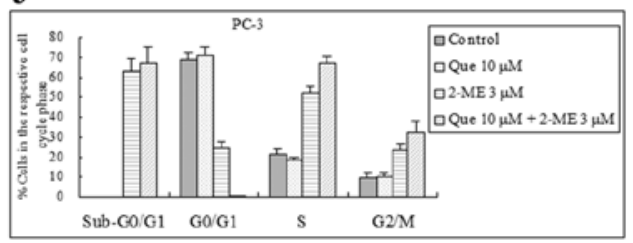

Figure 5. Effect of Que, 2-ME or combination on cell cycle distribution in LNCaP (A-D) or PC-3 (E-H) cells. (A and E) Control cells; (B and F) cells were treated with Que $10 \mu \mathrm{M}$ for $48 \mathrm{~h}$; (C and G) cells were treated with 2-ME $3 \mu \mathrm{M}$ for $48 \mathrm{~h}$; (D and H) cells were treated with Que $10 \mu \mathrm{M}+2$-ME $3 \mu \mathrm{M}$ for $48 \mathrm{~h}$. Distribution of cells in various phases was determined by flow cytometry. Representative histograms are shown in the top panel (A-H) and graphic presentation of the data shown in the bottom panel ( $\mathrm{I}$ and $\mathrm{J}$ ) is an average of three independent experiments.

cells using Annexin V binding assay. As shown in Fig. 4, the percentage of Annexin V (+) and PI (-) cells in the combination group were significantly increased $(80.2 \pm 7.1 \%$ for $\mathrm{LNCaP}$; $49.2 \pm 4.5 \%$ for $\mathrm{PC}-3 ; \mathrm{P}<0.05)$ as compared to the control $(1.3 \pm 0.5 \%$ for LNCaP; $3.8 \pm 1.1 \%$ for PC-3), quercetin alone (4.2 $\pm 2.6 \%$ for $\mathrm{LNCaP} ; 6.4 \pm 2.6 \%$ for $\mathrm{PC}-3)$ and $2-\mathrm{ME}$ alone (58.9 $\pm 6.4 \%$ for LNCaP; $27.3 \pm 3.4 \%$ for PC-3) for both $\mathrm{LNCaP}$ and PC- 3 cells.

Effect of quercetin with 2-ME treatment on the cell cycle. The cell cycle was examined after treatment. As shown in Fig. 5, the combination of quercetin and 2-ME treatment for $48 \mathrm{~h}$ resulted in a significant increase in $\mathrm{G} 2 / \mathrm{M}$ phase cells $(40.0 \pm 4.4 \%$ for $\mathrm{LNCaP} ; 32.1 \pm 5.8 \%$ for PC-3; $\mathrm{P}<0.05)$ as compared to the control $(12.8 \pm 1.6 \%$ for $\mathrm{LNCaP}$; $9.8 \pm 2.1 \%$ for PC-3), quercetin alone $(13.3 \pm 3.7 \%$ for $\mathrm{LNCaP}$; $10.4 \pm 1.4 \%$ for PC-3) and $2-\mathrm{ME}$ alone $(33.7 \pm 3.1 \%$ for LNCaP; $23.2 \pm 3.6 \%$ for PC-3). For PC-3 cells, the combination treatment resulted in a significant increase in the $\mathrm{S}$ phase cells $(67.4 \pm 3.2 \%, \mathrm{P}<0.05)$ as compared to the control $(21.9 \pm 2.3 \%)$, quercetin alone $(18.2 \pm 1.4 \%)$ and $2-\mathrm{ME}$ alone $(52.3 \pm 2.8 \%)$, with a significant decrease in the $\mathrm{G} 0 / \mathrm{G} 1$ phase cells $(0.5 \pm 0.2 \%, \mathrm{P}<0.05)$ as compared to the control $(68.3 \pm 4.1 \%)$, quercetin alone $(71.4 \pm 3.7 \%)$ and $2-\mathrm{ME}$ alone $(24.5 \pm 3.5 \%)$. A sub-G0/G1 peak appeared in the $2-\mathrm{ME}$ alone and combination treated PC-3 cells, however, there was no statistical significance between the percentages of cells in sub-G0/G1 phases $(63.1 \pm 5.9 \%$ for 2 -ME group; $67.6 \pm 5.3 \%$ for combination group).

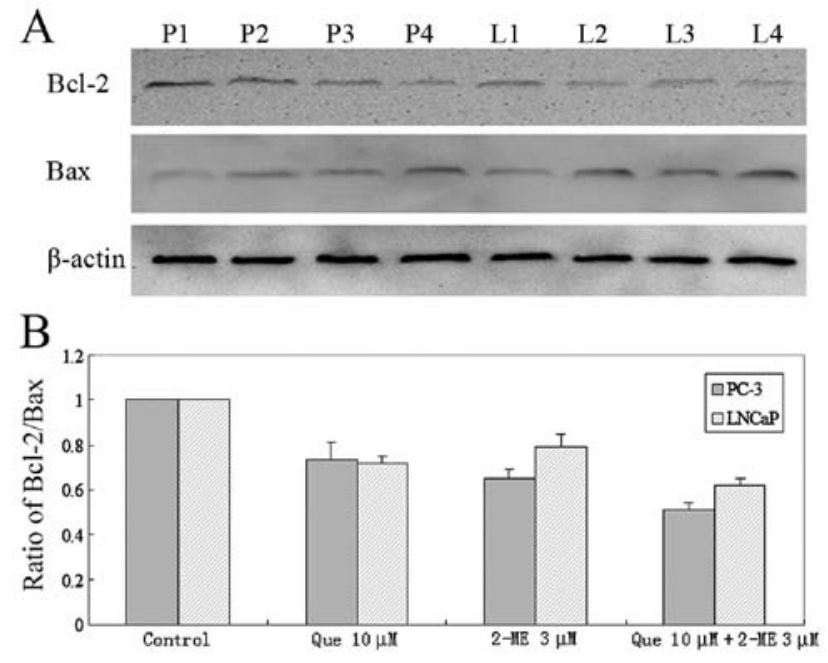

Figure 6. Effect of Que, 2-ME or combination on Bcl-2 and Bax expression in PC-3 or LNCaP cells. (P1 and L1) control cells; (P2 and L2) cells were treated with Que $10 \mu \mathrm{M}$ for $48 \mathrm{~h}$; (P3 and L3) cells were treated with 2-ME $3 \mu \mathrm{M}$ for $48 \mathrm{~h}$; (P4 and L4) cells were treated with Que $10 \mu \mathrm{M}+2-\mathrm{ME}$ $3 \mu \mathrm{M}$ for $48 \mathrm{~h}$. Expression of Bcl-2 and Bax was determined by western blot. Representative blots are shown in the top panel (A) and graphic presentation of the data is shown in the bottom panel (B) is an average of three independent experiments.

Effect of quercetin with 2-ME treatment on expression of Bcl-2 and Bax in prostate cancer cells. We investigated whether the combination of quercetin and 2-ME treatment for $48 \mathrm{~h}$ could induce apoptosis through regulation of anti-apoptotic 
Bcl-2 and proapoptotic Bax. As shown in Fig. 6, the expression of anti-apoptotic protein Bcl-2 decreased after treated with quercetin and 2-ME alone or in combination, whereas the expression of the proapoptotic protein Bax increased. The combination treatment of quercetin and 2-ME resulted in a significant decrease of Bcl-2/Bax ratio $(0.514 \pm 0.028$ for $\mathrm{PC}-3$; $0.618 \pm 0.034 \%$ for $\mathrm{LNCaP} ; \mathrm{P}<0.05)$ as compared to the control (1 for PC-3; 1 for LNCaP), quercetin alone $(0.734 \pm 0.073$ for PC-3; $0.718 \pm 0.032$ for LNCaP) and 2-ME alone $(0.647 \pm 0.043$ for PC-3; $0.792 \pm 0.058$ for LNCaP). These data indicate a potential role for $\mathrm{Bcl}-2 / \mathrm{Bax}$ ratio in drug-induced apoptosis in prostate cancer cells.

\section{Discussion}

Most patients with late prostate cancer treated with chemotherapy have temporary responses, associated with reduced quality of life due to the side effects of drugs (16). We aimed to evaluate new chemotherapeutic combinations based on two promising drugs for the treatment of prostate cancer. Drug combination has several advantages. Firstly, each drug has specific anticancer mechanism, leading to a wider spectrum of anticancer mechanism when combined. Secondly, certain drug may synergize with another. Finally, combination therapy with lower doses of each drug may be safer for long-term treatment and may lessen the drug-specific side-effect.

The combination of two drugs may generate synergism, additive effect or antagonism, which directly impacts the rationality and efficacy of the treatment. In this study, 4 different doses of each drug were selected based on the dose-effect curves, thus 16 different drug combinations were composed using factorial design, which could be used to study the fixed-dose combinations of two drugs (14). Our data showed that lower dose of quercetin $(<10 \mu \mathrm{M})$ with higher dose of 2-ME ( $>3 \mu \mathrm{M})$ for LNCaP cells, higher dose of quercetin $(>20 \mu \mathrm{M})$ with higher dose of $2-\mathrm{ME}(>3 \mu \mathrm{M})$ and Que $10 \mu \mathrm{M}$ with 2-ME $3 \mu \mathrm{M}$ for PC-3 cells showed synergistic activity. These data suggested that combination of quercetin and 2-ME at appropriate concentrations had the potential for greater antiproliferative activity. These data were consistent with the published results showing interaction between quercetin or 2-ME and other chemotherapeutic agents $(8,13,17)$.

Previous studies have shown that both quercetin alone and 2-ME alone can induce apoptosis in prostate cancer cells $(10,18)$. In our experiments, typical morphological changes of apoptotic cells were more evident in the combination group. Annexin V and PI staining showed that combination of quercetin and 2-ME induced a significant increase of apoptosis as compared to the drugs administered alone in both $\mathrm{LNCaP}$ and PC-3 cells. The results were consistent with a study treating human hepatoma cell lines with quercetin and 2-ME (19).

Vijayababu et al demonstrated that quercetin blocked G2/M transition and induced apoptosis in PC-3 cells (20). Kumar et al reported that 2-ME treatment arrested prostate cancer cells in G2/M phase, with a concomitant decrease in G1 population (10). Our data showed that for LNCaP cells, although a relative lower dose of quercetin $(10 \mu \mathrm{M})$ could not alter the cell cycle distribution obviously, its treatment with a higher dose of 2-ME $(3 \mu \mathrm{M})$ could induce a slight increase in $\mathrm{G} 2 / \mathrm{M}$ phase as compared to 2-ME alone. For PC-3 cells, as compared to the drugs administered alone, combination of quercetin and 2-ME arrested cells in $\mathrm{S}$ phase and G2/M phase, with a significant decrease in G0/G1 population. These data showed that the combination of quercetin and 2-ME could arrest LNCaP cells in G2/M phase and PC-3 cells in $\mathrm{S}$ phase and $\mathrm{G} 2 / \mathrm{M}$ phase, thus blocking the progress of cells to G0/G1 phase and inducing apoptosis. This advantage of drug combination was consistent with the cell proliferation data.

The mitochondrial pathway of apoptosis is mediated by the Bcl-2 family proteins whose members include proapoptotic

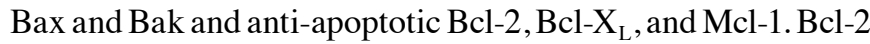
family proteins regulate the passage of small molecules, such as cytochrome $c$, Smac/Diablo, and apoptosis-inducing factor, which activates caspase cascades $(18,21)$. The activation of caspases is counteracted by anti-apoptotic members, because these proteins heterodimerize with proapoptotic members and interfere with release of cytochrome $c$ by pore-forming proteins (Bid, Bik) $(22,23)$. The relative ratio of proapoptotic and anti-apoptotic proteins determines the sensitivity or resistance of cells to various apoptotic stimuli $(21,24,25)$. Vijayababu et al showed that quercetin treatment significantly increased the expression of Bax and decreased the expression of Bcl-2 in a dose-dependent manner in PC-3 cells (20). Lee et al revealed that the apoptotic processes of LNCaP cells induced by quercetin were mediated by the dissociation of Bax from Bcl-xL and the activation of caspase families (18). Basu et al suggested that the phosphorylation of Bcl-xL induced by 2-ME might oppose the anti-apoptotic function of Bcl-xL to permit prostate cancer cells to undergo apoptosis (26). In the present study, we demonstrated that both a low dose of quercetin $(10 \mu \mathrm{M})$ alone and a high dose of 2-ME ( $3 \mu \mathrm{M})$ alone can increase the expression of Bax and decrease the expression of Bcl-2 in both LNCaP and PC-3 cells after treatment for $48 \mathrm{~h}$, furthermore, their combination enhanced these effects, with the ratio of $\mathrm{Bcl}-2 / \mathrm{Bax}$ decreasing more obviously.

In this study, we explored the potential treatment of quercetin combined with 2-ME in both androgen-dependent LNCaP and androgen-independent PC-3 human prostate cancer cell lines. Our findings showed synergistic inhibition of cell proliferation in both LNCaP and PC-3 cells, which have implications to clinicians. Since the regulation of proapoptotic Bax and anti-apoptotic Bcl-2 correlated well with the combination treatment to inhibit cell growth and inducing cell apoptosis, the combination treatment was more effective in inducing apoptosis through $\mathrm{Bcl}-2 / \mathrm{Bax}$-dependent mechanism than the single drug. Although the detail mechanism involved in anticancer activity needs further investigation, this study provided evidence that the treatment of quercetin combined with 2-ME enhanced the apoptotic action in human prostate cancer cells and raised the possibility of using these two anticancer drugs to treat prostate cancer.

\section{Acknowledgements}

This study was supported by the Beijing Natural Science Foundation (no. 7122075). 


\section{References}

1. Siegel R, Naishadham D and Jemal A: Cancer statistics, 2012 CA Cancer J Clin 62: 10-29, 2012.

2. Tannock IF, de Wit R, Berry WR, et al: Docetaxel plus prednisone or mitoxantrone plus prednisone for advanced prostate cancer. N Engl J Med 351: 1502-1512, 2004.

3. Berthold DR, Pond GR, Soban F, de Wit R, Eisenberger M and Tannock IF: Docetaxel plus prednisone or mitoxantrone plus prednisone for advanced prostate cancer: updated survival in the TAX 327 study. J Clin Oncol 26: 242-245, 2008.

4. Wenner CA, Martzen MR, Lu H, Verneris MR, Wang $\mathrm{H}$ and Slaton JW: Polysaccharide-K augments docetaxel-induced tumor suppression and antitumor immune response in an immunocompetent murine model of human prostate cancer. Int J Onco 40: 905-913, 2012

5. Kim MK, Park KS, Lee C, Park HR, Choo H and Chong Y: Enhanced stability and intracellular accumulation of quercetin by protection of the chemically or metabolically susceptible hydroxyl groups with a pivaloxymethyl (POM) promoiety. J Med Chem 53: 8597-8607, 2010.

6. Yuan ZP, Chen LJ, Fan LY, et al: Liposomal quercetin efficiently suppresses growth of solid tumors in murine models. Clin Cancer Res 12: 3193-3199, 2006.

7. Kumar R, Verma V, Jain A, Jain RK, Maikhuri JP and Gupta G: Synergistic chemoprotective mechanisms of dietary phytoestrogens in a select combination against prostate cancer. J Nutr Biochem 22: 723-731, 2011.

8. Hsieh TC and Wu JM: Targeting CWR22Rv1 prostate cancer cell proliferation and gene expression by combinations of the phytochemicals EGCG, genistein and quercetin. Anticancer Res 29: 4025-4032, 2009

9. Ma Z, Hung Nguyen T, Hoa Huynh T, Tien Do P and Huynh H: Reduction of rat prostate weight by combined quercetinfinasteride treatment is associated with cell cycle deregulation. J Endocrinol 181: 493-507, 2004.

10. Kumar AP, Garcia GE and Slaga TJ: 2-methoxyestradiol blocks cell-cycle progression at $\mathrm{G}(2) / \mathrm{M}$ phase and inhibits growth of human prostate cancer cells. Mol Carcinog 31: 111-124, 2001.

11. Fotsis T, Zhang Y, Pepper MS, et al: The endogenous oestrogen metabolite 2-methoxyoestradiol inhibits angiogenesis and suppresses tumour growth. Nature 368: 237-239, 1994.

12. Sweeney C, Liu G, Yiannoutsos C, et al: A phase II multicenter, randomized, double-blind, safety trial assessing the pharmacokinetics, pharmacodynamics, and efficacy of oral 2 -methoxyestradiol capsules in hormone-refractory prostate cancer. Clin Cancer Res 11: 6625-6633, 2005.

13. Ghosh R, Ganapathy M, Alworth WL, Chan DC and Kumar AP: Combination of 2-methoxyestradiol (2-ME2) and eugenol for apoptosis induction synergistically in androgen independent prostate cancer cells. J Steroid Biochem Mol Biol 113: 25-35, 2009.
14. Ram CV: Antihypertensive efficacy of angiotensin receptor blockers in combination with hydrochlorothiazide: a review of the factorial-design studies. J Clin Hypertens (Greenwich) 6: 569-577, 2004

15. Chou TC and Talalay P: Quantitative analysis of dose-effect relationships: the combined effects of multiple drugs or enzyme inhibitors. Adv Enzyme Regul 22: 27-55, 1984.

16. Smith DC, Tangen CM, Van Veldhuizen PJ Jr, et al: Phase II evaluation of early oral estramustine, oral etoposide, and intravenous paclitaxel combined with hormonal therapy in patients with high-risk metastatic prostate adenocarcinoma: Southwest Oncology Group S0032. Urology 77: 1172-1176, 2011.

17. Nair SK, Verma A, Thomas TJ, et al: Synergistic apoptosis of MCF-7 breast cancer cells by 2-methoxyestradiol and bis(ethyl) norspermine. Cancer Lett 250: 311-322, 2007.

18. Lee DH, Szczepanski M and Lee YJ: Role of Bax in quercetininduced apoptosis in human prostate cancer cells. Biochem Pharmacol 75: 2345-2355, 2008

19. Chang YF, Hsu YC, Hung HF, et al: Quercetin induces oxidative stress and potentiates the apoptotic action of 2-methoxyestradiol in human hepatoma cells. Nutr Cancer 61: 735-745, 2009.

20. Vijayababu MR, Kanagaraj P, Arunkumar A, Ilangovan R, Aruldhas MM and Arunakaran J: Quercetin-induced growth inhibition and cell death in prostatic carcinoma cells (PC-3) are associated with increase in p21 and hypophosphorylated retinoblastoma proteins expression. J Cancer Res Clin Oncol 131: 765-771, 2005.

21. Shabbits JA, Hu Y and Mayer LD: Tumor chemosensitization strategies based on apoptosis manipulations. Mol Cancer Ther 2: 805-813, 2003

22. Gross A, McDonnell JM and Korsmeyer SJ: BCL-2 family members and the mitochondria in apoptosis. Genes Dev 13 1899-1911, 1999.

23. Martinou JC and Youle RJ: Mitochondria in apoptosis: Bcl-2 family members and mitochondrial dynamics. Dev Cell 21: 92-101, 2011.

24. Zhou C, Li X, Du W, et al: Antitumor effects of ginkgolic acid in human cancer cell occur via cell cycle arrest and decrease the Bcl-2/Bax ratio to induce apoptosis. Chemotherapy 56: 393-402, 2010.

25. Xu G, Gong Z, Yu W, Gao L, He S and Qian Z: Increased expression ratio of $\mathrm{Bcl}-2 / \mathrm{Bax}$ is associated with crocin-mediated apoptosis in bovine aortic endothelial cells. Basic Clin Pharmacol Toxicol 100: 31-35, 2007.

26. Basu A and Haldar S: Identification of a novel Bcl-xL phosphorylation site regulating the sensitivity of taxol- or 2-methoxyestradiol-induced apoptosis. FEBS Lett 538: 41-47, 2003. 